\title{
Levels of public awareness regarding cervical spine injury and the suitable first aid response among adults in Saudi Arabia
}

\author{
Mohammed L. Al-Otaibi, MD, FRCSC, Khalid H. Almutairi, Medical Student, Khalid M. Al-Otaibi, Medical Student, \\ Abdulelah N. Alghaeb, Medical Student, Saeed H. Al-Hadi, Medical Student.
}

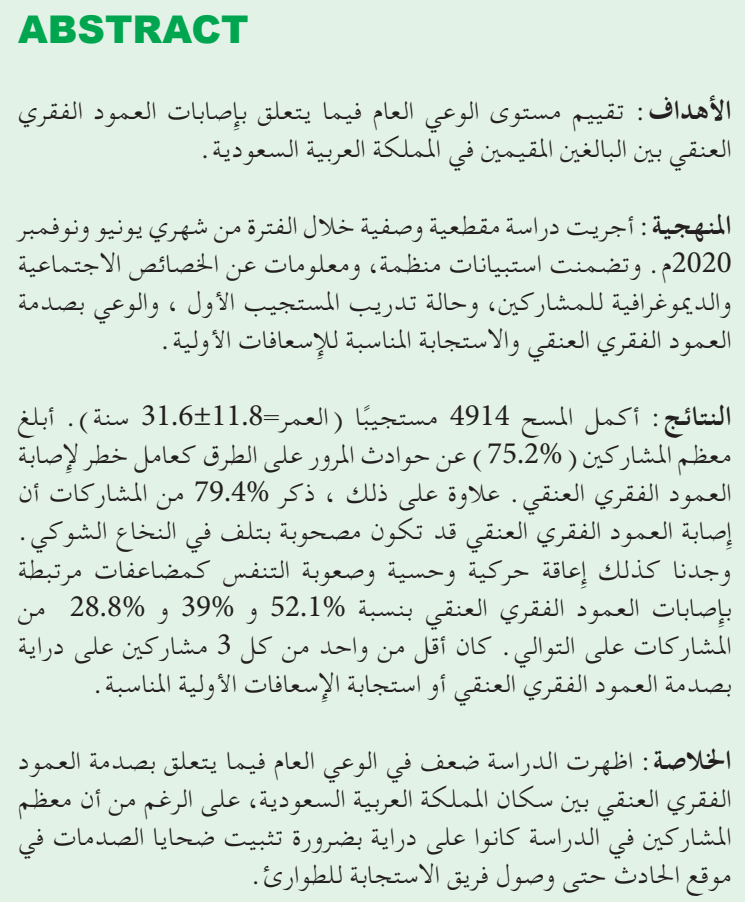

Objectives: To evaluate the level of public awareness regarding cervical spine injuries among adult residents of the Kingdom of Saudi Arabia (KSA).

Methods: This descriptive cross-sectional study was carried out between June and November 2020. It involved structured questionnaires, collecting information on participant socio-demographic characteristics, first responder training status, and the awareness of cervical spine trauma and suitable first aid response.

Results: A total of 4914 respondents (age, $31.6 \pm$ 11.8 years) completed the survey. Most participants $(75.2 \%)$ reported road traffic accidents as a risk factor for cervical spine injury. Moreover, $79.4 \%$ of the participants reported that cervical spine injury may be accompanied by damage to the spinal cord. Motor and sensory disability, and trouble breathing were recognized as complications associated with cervical spine injuries by $52.1 \%, 39 \%$, and $28.8 \%$ of the participants, respectively. Fewer than one in 3 participants was aware of cervical spine trauma or the suitable first aid response.

Conclusion: Public awareness regarding cervical spine trauma is poor among the KSA residents, although most study participants were aware trauma victims should be immobilized at the site of the accident until the arrival of an emergency response team.

Keywords: cervical spine, public awareness, emergency, trauma, spinal cord

Saudi Med J 2021; Vol. 42 (5): 543-549

doi: 10.15537/smj.2021.42.5.20200760

From the Department of Orthopedic (Al-Otaibi $M$ ) and from the College of Medicine (Almutairi, Al-Otaibi K, Alghaeb, Al-Hadi), King Khalid University, Abha, Kingdom of Saudi Arabia.

Received 5th November 2020. Accepted 22nd March 20201.

Address correspondence and reprint request to: Dr. Mohammed L. Al-Otaibi, Department of Orthopedic, College of Medicine, King Khalid University, Abha, Kingdom of Saudi Arabia. E-mail:mlalotaibi@kku.edu.sa

ORCID ID: https://orcid.org/0000-0002-0469-3882

W orldwide victims of trauma due to road traffic accidents (RTAs), fall from heights or workplace injuries have gained authorities attention to increase public awareness towards the safe way to respond to these injuries. Cervical spine injuries are rare but can cause significant life-long disability. The cervical spine includes 7 vertebrae and that protect the spinal cord; ${ }^{1,2}$ however, its anatomical structure and the associated flexibility make it vulnerable to injury. ${ }^{3}$ Different types of 
injury are associated with distinct mechanisms. Trauma is the most common cause of cervical spine injury, including that resulting from RTAs, falls, penetrating or blunt trauma, and sports-related injuries. ${ }^{4,5}$ Nontrauma-related causes include compression fractures from osteoporosis, arthritis, cancer, and inflammation of the spinal cord. Cervical injury tends to occur due to the flexion, extension, rotation, contusion, or compression of the spinal cord. ${ }^{6}$

The management of cervical disc injuries requires a highly qualified team that includes a trauma surgeon, anesthesiologist, emergency department physician, and nurse practitioner, among others. In the immediate aftermath of an injury, it is paramount that the patient remains still, and that neck movements are minimized, maintaining the stability of the cervical spine, in particular, during transport. ${ }^{7,8}$ Poor management of cervical spine injury may lead to respiratory and cardiovascular function defects due to neurological deficits associated with the injury. ${ }^{9}$ Injured cervical spine tends to be unstable; in fact, failure to stabilize it prior to a definitive treatment increases the risk of secondary injury to the spinal cord. ${ }^{10}$

Public awareness regarding cervical spine trauma and the suitable first aid response is crucial, as every person is at risk of such injury, which may occur as a result of an RTA or a fall. Proper handling of such cases until the arrival of an emergency response team may save victims' lives or prevent permanent damage or disability. The present study is aimed to assess the levels of public awareness regarding cervical spine trauma, the signs indicative of trauma, and the suitable first aid response among the adult residents of the Kingdom of Saudi Arabia (KSA).

Methods. The study protocol received ethical approval (No. ECM \#2020-1209) from the Research Ethics Committee at King Khalid University, Abha, KSA. This study used a cross-sectional design, targeting the KSA residents aged 18 years or older and willing to participate in the study. Data were collected using a structured self-administered online questionnaire. The questionnaire was uploaded onto social media platforms by the researchers and their relatives and friends between June and November 2020. All accessible and

Disclosure. Authors have no conflict of interests, and the work was not supported or funded by any drug company. eligible individuals were invited to complete the online questionnaire. The questionnaire was created for the purpose of this study, based on the extensive literature review and consultation with a panel of 5 experts in spine surgery, orthopedics and emergency medicine affiliated with the Medical College of King Khalid University, Abha, KSA invited to verify the tool's clarity and validity. The questionnaire included 3 sections. The first section enquired on participants' sociodemographic characteristics, including information on trauma response training. The second section examined the participants' levels of awareness regarding cervical spine injury, including the knowledge of associated risk factors, complications, causes, clinical presentation, and the suitable first aid response, for example, immobilization. The third section collected information on the participants' declared response to patients with cervical spine trauma. The inclusion criteria were all adults excluding minors.

Statistical analysis. Raw data were coded and input in Statistical Package for Social Sciences for Windows, version 22 (IBMCorp, Armonk, NY, USA). All statistical analyses were performed using 2-tailed tests. $P$-values of $<0.05$ were considered indicative of a statistically significant finding. The levels of awareness were quantified by summing up the scores obtained for each awareness-related item, whereby correct answers were assigned one point. A score of $<60 \%$ of the total number of points represented "poor" awareness; in contrast, a score of $>60 \%$ of the total number of points represented "good" awareness. Demographic characteristics, the overall levels of awareness, and participants' declared interventions were reported as descriptive statistics, using frequencies and percentages. Cross-tabulation was used to assess the levels of awareness according to participants' characteristics and first aid training status; these associations were assessed using the Pearson Chi-square test.

Results. A total of 4914 respondents $(58.3 \%$ male, $41.9 \%$ university graduates, and $32.6 \%$ students) completed the survey. Participant age ranged from 18 to 65 years, with the mean age of $31.6 \pm 11.8$ years. A total of $50.2 \%$ of the respondents had a monthly income of $<5000$ SR. A total of $46.4 \%$ respondents were married and $19.1 \%$ were trained emergency responders (Table 1 ).

Table 2 present survey findings regarding the levels of public awareness of cervical spine trauma. Most respondents (75.2\%) knew of RTAs as risk factors for cervical spine injury; meanwhile, $15.6 \%$ knew of no such risk factors. Moreover, $79.4 \%$ of the participants reported that cervical spine injury could be accompanied 
Table 1 - Sociodemographic characteristics of the study participants (Saudi Arabia).

\begin{tabular}{lrc}
\hline Characteristics & $\mathbf{n}$ & $(\%)$ \\
\hline Age, years & & \\
$<20$ & 790 & $(16.1)$ \\
$21-30$ & 2088 & $(42.5)$ \\
$31-40$ & 783 & $(15.9)$ \\
$41-50$ & 828 & $(16.8)$ \\
$50+$ & 425 & $(8.6)$ \\
Gender & & \\
Male & 2865 & $(58.3)$ \\
Female & 2049 & $(41.7)$ \\
Educational level & & \\
Secondary or below & 1251 & $(25.5)$ \\
University student & 1603 & $(32.6)$ \\
University/above & 2060 & $(41.9)$ \\
Monthly income, SAR & & \\
$\quad<5000$ & 2466 & $(50.2)$ \\
5000-10000 & 1155 & $(23.5)$ \\
$\quad>10000$ & 1293 & $(26.3)$ \\
Marital status & & \\
Single & & \\
Married & 2483 & $(50.5)$ \\
Divorced/widowed & 2280 & $(46.4)$ \\
Trained as first responder & 151 & $(3.1)$ \\
Yes & & \\
No & 941 & $(19.1)$ \\
& 3973 & $(80.9)$ \\
\hline
\end{tabular}

by damage to the spinal cord, while $71.3 \%$ of the participants reported that injuries to the cervical spine could lead to life-long disability. Motor and sensory disability, and breathing problems were recognized as cervical spine injury complications by $52.1 \%$, 39\%, and $28.8 \%$ of the participants, respectively. Finally, $55.1 \%$ of the respondents reported that patients with cervical spine injury may require life-long medical and physical management.

A total of $46.9 \%$ and $37.4 \%$ of the participants, respectively, reported calling an emergency response team and minimizing movement during transportation as the suitable first aid measures in cases of cervical spine injury. Approximately $78 \%$ and $68.4 \%$ of the participants knew that early diagnosis of cervical spine injury can help prevent future complications and that proper management at the accident site can prevent permanent spinal cord damage, respectively. The most commonly $(72.9 \%)$ reported way of immobilizing patients was keeping them in the same position until the arrival of an emergency response team, provided the location was secure. In cases requiring resuscitation,
Table 2 - Public awareness of the correct response to cervical spine trauma among Saudi Arabia residents.

\begin{tabular}{|c|c|c|}
\hline Response & $\mathrm{n}$ & $(\%$ \\
\hline \multicolumn{3}{|l|}{ Cervical injury risk factors } \\
\hline RTA & 3695 & $(75.2)$ \\
\hline Sports & 99 & $(2.0)$ \\
\hline Inflammation & 208 & $(4.2)$ \\
\hline Tumor & 123 & $(2.5)$ \\
\hline Long use of devices & 10 & $(0.2)$ \\
\hline Incorrect sitting posture & 6 & $(0.1)$ \\
\hline Fall & 5 & $(0.1)$ \\
\hline Do not know & 768 & $(15.6)$ \\
\hline \multicolumn{3}{|l|}{$\begin{array}{l}\text { Is it possible for a cervical spine injury to be } \\
\text { accompanied by damage to the spinal cord? }\end{array}$} \\
\hline Yes & 3900 & $(79.4)$ \\
\hline No & 84 & $(1.7)$ \\
\hline Do not know & 930 & $(18.9)$ \\
\hline \multicolumn{3}{|c|}{$\begin{array}{l}\text { Can injuries to the cervical spine lead to life-long } \\
\text { disability? }\end{array}$} \\
\hline Yes & 3502 & $(71.3)$ \\
\hline No & 222 & $(4.5)$ \\
\hline Do not know & 1190 & $(24.2)$ \\
\hline \multicolumn{3}{|l|}{ Complications of cervical injury } \\
\hline Motor disability & 2559 & $(52.1)$ \\
\hline Sensory disability & 1918 & $(39.0)$ \\
\hline Affected breathing & 1414 & $(28.8)$ \\
\hline Urine incontinence & 1191 & $(24.2)$ \\
\hline Stool incontinence & 1132 & $(23.0)$ \\
\hline Smell \& taste problems & 386 & $(7.9)$ \\
\hline Do not know & 2249 & $(45.8)$ \\
\hline \multicolumn{3}{|c|}{$\begin{array}{l}\text { May a patient with cervical spine injury require } \\
\text { medical and physical management for their whole } \\
\text { life? }\end{array}$} \\
\hline Yes & 2707 & $(55.1)$ \\
\hline No & 624 & $(12.7)$ \\
\hline Do not know & 1583 & $(32.2)$ \\
\hline \multicolumn{3}{|l|}{$\begin{array}{l}\text { The first management for cervical spine injury } \\
\text { patient }\end{array}$} \\
\hline Minimizing movement during transport & 1838 & $(37.4)$ \\
\hline Changing patient position & 84 & $(1.7)$ \\
\hline Call emergency services & 2304 & $(46.9)$ \\
\hline Do not know & 688 & $(14.0)$ \\
\hline \multicolumn{3}{|c|}{$\begin{array}{l}\text { Early prediction of cervical spine injury will help in } \\
\text { preventing complications }\end{array}$} \\
\hline Yes & 3818 & $(77.7)$ \\
\hline No & 179 & $(3.6)$ \\
\hline Do not know & 917 & $(18.7)$ \\
\hline \multicolumn{3}{|c|}{$\begin{array}{l}\text { Proper management at accident cite may prevent } \\
\text { permanent spinal cord damage }\end{array}$} \\
\hline Yes & 3292 & $(68.4)$ \\
\hline No & 371 & $(7.7)$ \\
\hline Do not know & 1153 & $(23.9)$ \\
\hline
\end{tabular}

RTA: road traffic accidents 
86.3\% of the respondents declared they would call for an emergency response team and start resuscitation while ensuring spine immobilization. The respondents declared that the following signs were indicative of a cervical spinal cord injury: inability to move hands (32.9\%), numbness $(24.3 \%)$, pain in the arms $(15.7 \%)$, and neck deformity (12.8\%); a total of $60.8 \%$ of the respondents recognized all these signs as indicative of cervical spine injury. Among diseases that increase the risk of cervical spine injury, the participants recognized rheumatoid arthritis (74.5\%), obesity (41.9\%), and diabetes mellitus (16.6\%). Overall, 1565 (31.8\%) participants had good awareness of cervical spine trauma and management.

Table 2 - Public awareness of the correct response to cervical spine trauma among Saudi Arabia residents (continuation).

\begin{tabular}{|c|c|c|}
\hline Response & $\mathbf{n}$ & (\%) \\
\hline \multicolumn{3}{|l|}{$\begin{array}{l}\text { To safely stabilize a patient requires which of the } \\
\text { following }\end{array}$} \\
\hline $\begin{array}{l}\text { Keeping the patient same position if the place is } \\
\text { safe until emergency services arrive }\end{array}$ & 3582 & $(72.9)$ \\
\hline Correct deformity pulls arms neck and Legs & 398 & $(8.1)$ \\
\hline Set patient up & 41 & $(0.8)$ \\
\hline Do not know & 893 & $(18.2)$ \\
\hline \multicolumn{3}{|l|}{$\begin{array}{l}\text { How would you respond should the patient require } \\
\text { resuscitation? }\end{array}$} \\
\hline $\begin{array}{l}\text { Call emergency services, start resuscitation, } \\
\text { ensuring spine immobilization }\end{array}$ & 4243 & $(86.3)$ \\
\hline Transport patient to nearest hospital in my vehicle & 83 & $(1.7)$ \\
\hline Do nothing & 91 & $(1.8)$ \\
\hline Do not know & 497 & $(10.1)$ \\
\hline \multicolumn{3}{|l|}{$\begin{array}{l}\text { Which of the following signs may be indicative of a } \\
\text { cervical cord injury? }\end{array}$} \\
\hline Unable to move hand & 1618 & $(32.9)$ \\
\hline Pain in arms & 770 & $(15.7)$ \\
\hline Numbness & 1195 & $(24.3)$ \\
\hline Neck deformity & 629 & $(12.8)$ \\
\hline All of the above & 2989 & $(60.8)$ \\
\hline Do not know & 68 & $(1.4)$ \\
\hline \multicolumn{3}{|l|}{$\begin{array}{l}\text { Which of the following diseases may increase the risk } \\
\text { of cervical spine injury? }\end{array}$} \\
\hline Down's syndrome & 745 & $(15.2)$ \\
\hline Rheumatoid arthritis & 3660 & $(74.5)$ \\
\hline Diabetes milieus & 818 & (16.6) \\
\hline Obesity & 2060 & $(41.9)$ \\
\hline \multicolumn{3}{|l|}{ Overall awareness level } \\
\hline Poor & 3349 & $(68.2)$ \\
\hline Good & 1565 & $(31.8)$ \\
\hline
\end{tabular}

Table 3 presents the findings regarding the participants' declared responses to witnessing cervical spine injury. A total of $73.5 \%$ of the participants reported that they would help the victims of RTAs or falls. In addition, $85.4 \%$ of the participants agreed that a suitable response could help the victims, while $71.2 \%$ of the participants reported that spinal injury may permanently reduce the victim's quality of life. The need for spinal movement precautions in unconscious trauma patients was reported by $82.4 \%$ of the participants. A total of $93.1 \%$ of the respondents declared that they

Table 3 - Self-reported first responses to witnessed cervical spine injury among Saudi Arabia residents.

\begin{tabular}{|c|c|c|}
\hline Responses & n & $(\%)$ \\
\hline \multicolumn{3}{|l|}{$\begin{array}{l}\text { I will help people involved in a car accident } \\
\text { or fall }\end{array}$} \\
\hline Yes & 3614 & $(73.5)$ \\
\hline No & 1300 & $(26.5)$ \\
\hline \multicolumn{3}{|l|}{ A proper response can help the victim } \\
\hline Yes & 4197 & $(85.4)$ \\
\hline No & 113 & $(2.3)$ \\
\hline Do not know & 604 & $(12.3)$ \\
\hline \multicolumn{3}{|l|}{$\begin{array}{l}\text { Cervical spine injury can affect patient quality } \\
\text { of life until death }\end{array}$} \\
\hline Yes & 3501 & $(71.2)$ \\
\hline No & 274 & $(5.6)$ \\
\hline Do not know & 1139 & $(23.2)$ \\
\hline \multicolumn{3}{|l|}{$\begin{array}{l}\text { I would take spinal movement precaution in an } \\
\text { unconscious trauma patient }\end{array}$} \\
\hline Yes & 4047 & $(82.4)$ \\
\hline No & 867 & $(17.6)$ \\
\hline \multicolumn{3}{|l|}{$\begin{array}{l}\text { I will try not to move the patient and call } \\
\text { emergency services }\end{array}$} \\
\hline Yes & 4573 & $(93.1)$ \\
\hline No & 122 & $(2.5)$ \\
\hline Do not know & 219 & $(4.5)$ \\
\hline \multicolumn{3}{|l|}{$\begin{array}{l}\text { I will call emergency services before beginning } \\
\text { first aid intervention }\end{array}$} \\
\hline Yes & 4171 & $(84.9)$ \\
\hline No & 743 & $(15.1)$ \\
\hline \multicolumn{3}{|l|}{$\begin{array}{l}\text { I will take extreme care at all times to maintain } \\
\text { the alignment of the head, neck and spine }\end{array}$} \\
\hline Yes & 4717 & $(96.0)$ \\
\hline No & 197 & $(4.0)$ \\
\hline \multicolumn{3}{|l|}{$\begin{array}{l}\text { If the patient is responsive and I suspect cervical } \\
\text { spine injury I will do the following }\end{array}$} \\
\hline Reassure them and tell them to remain still & 4119 & $(83.8)$ \\
\hline Check their neck mobility & 249 & $(5.1)$ \\
\hline Try to change their position & 54 & $(1.1)$ \\
\hline Do not know & 492 & $(10.0)$ \\
\hline
\end{tabular}


would try not to move the patient and that they would call an emergency response team instead. Moreover, $84.9 \%$ of the participants reported that they would call for an emergency response team before delivering any first aid interventions. A total of $96 \%$ of the participants declared they would take extreme care to maintain the alignment of the head, neck, and spine; finally, 83.8\% of the respondents declared they would reassure trauma victims with suspected cervical spine injury and tell them not to move, if they were responsive.

Table 4 presents the levels of public awareness regarding cervical spine trauma, stratified by participant characteristics. Good awareness was detected among $58.4 \%$ of older adult participants and $16.1 \%$ aged $<20$ years; this difference was statistically significant ( $p=0.001$ ). Moreover, $43.3 \%$ of the participating men and $15.8 \%$ women, had good awareness of these injuries $(p=0.001)$. Furthermore, good awareness

Table 4 - Levels of public awareness regarding cervical spine trauma, stratified by survey participant demographic characteristics

Awareness level

\begin{tabular}{|c|c|c|c|c|c|}
\hline Variables & \multicolumn{2}{|c|}{ Poor } & \multicolumn{2}{|c|}{ Good } & $P$-value \\
\hline \multicolumn{6}{|l|}{ Age, years } \\
\hline$<20$ & 663 & $(72.9)$ & 127 & $(16.1)$ & \multirow{5}{*}{$0.001^{*}$} \\
\hline $21-31$ & 1593 & $(76.3)$ & 495 & $(23.7)$ & \\
\hline $31-40$ & 576 & $(73.6)$ & 207 & $(26.4)$ & \\
\hline $41-50$ & 340 & $(41.1)$ & 488 & $(58.9)$ & \\
\hline $50+$ & 177 & $(41.6)$ & 248 & $(58.4)$ & \\
\hline \multicolumn{6}{|l|}{ Gender } \\
\hline Male & 1624 & $(59.7)$ & 1241 & $(43.3)$ & \multirow{2}{*}{$0.001^{*}$} \\
\hline Female & 1725 & $(84.2)$ & 324 & $(15.8)$ & \\
\hline \multicolumn{6}{|l|}{ Educational level } \\
\hline Secondary or below & 860 & $(68.7)$ & 391 & $(31.3)$ & \multirow{3}{*}{$0.002^{*}$} \\
\hline University student & 1273 & $(79.4)$ & 330 & $(20.6)$ & \\
\hline University/above & 1216 & $(59.0)$ & 844 & $(41.0)$ & \\
\hline \multicolumn{6}{|c|}{ Monthly income, Saudi Riyals } \\
\hline$<5000$ & 1970 & $(79.9)$ & 496 & $(20.1)$ & \multirow{3}{*}{$0.001^{*}$} \\
\hline $5000-10000$ & 747 & $(64.7)$ & 408 & $(35.3)$ & \\
\hline$>10000$ & 632 & $(48.9)$ & 661 & $(51.1)$ & \\
\hline \multicolumn{6}{|l|}{ Marital status } \\
\hline Single & 1918 & $(77.2)$ & 565 & $(22.8)$ & \multirow{3}{*}{$0.058^{*}$} \\
\hline Married & 1339 & $(58.3)$ & 941 & $(41.3)$ & \\
\hline Divorced/widowed & 92 & $(60.9)$ & 59 & $(39.1)$ & \\
\hline \multicolumn{6}{|c|}{ Trained as first responder } \\
\hline Yes & 27 & $(2.9)$ & 914 & $(97.1)$ & \multirow{2}{*}{0.001} \\
\hline No & 3322 & $(83.6)$ & 651 & $(16.4)$ & \\
\hline \multicolumn{6}{|c|}{$\begin{array}{l}\text { Values are presented as number and percentage }(\%) \text {. Comparisons } \\
\text { were performed with the Pearson } \mathrm{x}^{2} \text { test. }{ }^{*} P \text {-value of }<0.05 \text { was } \\
\text { considered indicative of a statistically significant difference. }\end{array}$} \\
\hline
\end{tabular}

was detected among $41 \%$ of university graduates and $31.3 \%$ participants with a lower educational attainment $(p=0.002)$. Finally, $97.1 \%$ of the participants who were trained and $16.4 \%$ were not trained as trauma first responders, had good awareness of cervical spine injuries $(p=0.001)$.

Discussion. The present study is aimed to assess the levels of public awareness regarding cervical spine trauma and the suitable form of first aid response. Appropriate evaluation and protection of the cervical spine during resuscitation after trauma is challenging. Improper handling of a patient with cervical trauma can cause permanent disability or death. ${ }^{11-13}$ Proper management confirms that excessive movement may aggravate any initial damage to the spine, thus increasing the chance of a secondary injury. The initial assessment of a cervical spine injury can be difficult, in particular, when there are no obvious signs or symptoms. An assessment in the field requires the evaluation of patient consciousness, airway obstruction, breathing pattern, and circulatory function to detect any signs of injury. In the absence of any life-threatening conditions, the level of consciousness of the individual should be determined and a neurological assessment should be performed. ${ }^{14,15}$ In conscious patients, the evaluation should start with inquiring regarding feelings of numbness, painful dysesthesias or paresthesia, weakness, or neck pain. An initial examination can detect apparent neurological deficits, which can manifest as a partial or total loss of ability to move limbs, gross weakness, numbness, or significant pain on palpation of the cervical region. ${ }^{16,17}$ Knowing the suitable type of first aid response to cervical spine trauma may save a patient's life.

Road traffic accidents was a commonly recognized risk factor for cervical spine trauma among the present study participants; RTA is the leading cause of trauma in Saudi Arabia. ${ }^{18,19}$ Other risk factors such as sports and falls have been reported. Moreover, the present study revealed that more than $3 \%$ of the participants knew that cervical spine injury could be accompanied by damage to the spinal cord, which may result in life-long disability. Motor disabilities and sensory disabilities, followed by urinary and stool incontinence, were identified by the study participants as common complications of cervical spine injuries. The current study participants were aware that life-long disability resulting from cervical spine injury may increase the patients' need for long-term medical and physical management.

In the present study, nearly two-thirds of the participants recognized the main signs of cervical spine 
injury, and approximately $75 \%$ of participants knew how to safely immobilize a patient with such an injury. Concurrently, fewer than one in 2 of the respondents knew the number to call to summon an emergency response team that could attend to such a case. In total, one-third of the study participants had good awareness of cervical spine trauma and the suitable first aid response. The awareness level was higher among the older and male participants than among their counterparts, likely due to previous experience with similar injuries. Moreover, having attained higher levels of education and having a history of first aid training were associated with higher levels of cervical spine injury awareness.

A previous study by Samamni et $\mathrm{al}^{20}$ examined the levels of awareness regarding the "text neck" syndrome among young adults. The study revealed that 35\% of young adults had heard of the "text neck" syndrome, but only $8 \%$ of the study participants knew what it entailed, while $21 \%$ of the them knew how to prevent it. A separate study assessed the levels of public awareness of spinal injuries in the KSA population. ${ }^{21}$ Most of the participants had good knowledge regarding the basic structures of the spine; approximately $45.9 \%$ of them knew the clinical features of spinal cord injury. Males were significantly more knowledgeable. The respondents' level of education was significantly associated with the extent of their knowledge of spine anatomy and injury.

In the present study, approximately $75 \%$ of the respondents reported that they would help patients with cervical spine trauma, as their prompt response could prevent permanent disability. Moreover, nearly all of the participants (93\%) reported that they would not move the patient and that they would call for an emergency response team, except for cases that may require urgent help. Furthermore, more than $95 \%$ of the participants said that they would aim to maintain the alignment of the head, neck, and spine to prevent secondary injury.

Study limitations. The main limitations of our study can be its design lacking utilization of further explanatory roles aiming to better explain the questionnaire items to participants assuring full understanding of the questions and use of links and web sites with educational materials and videos to help the educate public and to compare pre and post questionnaire answering knowledge.

In conclusion, the present study findings suggest that the levels of public awareness regarding cervical spine trauma is low among the KSA population, except for the need of immobilization until the arrival of an emergency response team at the accident site. In the present study, most of the participants did not know the emergency number to call or how to provide resuscitation. The levels of public awareness of cervical spine trauma and the suitable first aid response require improvement, as these types of injury can be fatal, while a suitable response may prevent complications or death. This improvement can be achieved by providing health education sessions through mass or social media, and by education first aid in school and university curriculums.

Acknowledgment. The authors gratefully acknowledge Editage (www.editage.com) for English language editing.

\section{References}

1. Whyte T, Stuart CA, Mallory A, Ghajari M, Plant DJ, Siegmund GP, et al. A review of impact testing methods for headgear in sports: considerations for improved prevention of head injury through research and standards. J Biomech Eng 2019; 141: 070803.

2. Kong TH, Lee JW, Park YA, Seo YJ. Clinical features of fracture versus concussion of the temporal bone after head trauma. J Audiol Otol 2019; 23: 96-102.

3. Hale AT, Say I, Shah S, Dewan MC, Anderson RC, Tomycz LD. Traumatic occipitocervical distraction injuries in children: A systematic review. Pediatr Neurosurg 2019; 54: 75-84.

4. Shafafy R, Valsamis EM, Luck J, Dimock R, Rampersad $S$, Kieffer W, et al. Predictors of mortality in the elderly patient with a fracture of the odontoid process: can we use non-spinal scoring systems? Bone Joint J 2019; 101: 253-259.

5. Rief M, Zoidl P, Zajic P, Heschl S, Orlob S, Silbernagel G, et al. Atlanto-occipital dislocation in a patient presenting with out-of-hospital cardiac arrest: a case report and literature review. J Med Case Rep 2019; 13: 44.

6. PATENTSCOPE Wipo IP Portal. US4194501-First aid splint for cervical spine injuries. [cited 2021; accessed 2021 April 5]. Available from URL: https://patentscope.wipo. int/search/es/detail.jsf;jsessionid=F45349AF0828B2A00 C2790D8E53E5240.wapp2nA?docId=US37130696\&_ cid=P20-KB8CNW-87407-49

7. Yisheng W, Fuying Z, Limin W, Junwei L, Guofu P, Weidong W. First aid and treatment for cervical spinal cord injury with fracture and dislocation. Indian $J$ Orthop 2007; 41: 300-304.

8. Timothy J, Towns G, Girn HS. Cervical spine injuries. Current Orthopaedics 2004; 18: 1-6.

9. Kwon BK, Vaccaro AR, Grauer JN, Fisher CG, Dvorak MF. Subaxial cervical spine trauma. J Am Acad Orthop Surg 2006; 14: 78-89. 
10. Coleman WP, Benzel E, Cahill DW, Ducker T, Geisler F, Green B, et al. A critical appraisal of the reporting of the National Acute Spinal Cord Injury Studies (II and III) of methylprednisolone in acute spinal cord injury. J Spinal Disord 2000; 13: 185-199.

11. Aiker GJ, Oh YS, Leslie EV, Lehotay J, Panaro VA, Eschner EG. Postmortem radiology of head and neck injuries in fatal traffic accidents. Radiology 1975; 114: 611-617.

12. Taylor JR. Cervical spinal injuries in fatal motor vehicle trauma. In Biomechanics of Neck Injury: Proceedings of a Seminar, The 1995 (p. 11). Institution of Engineers, Australia. [Updated 1995; Accessed on 2021 April 5]. Available from: https://trid.trb.org/view/575795

13. US Department of Commerce Patent and Trademark Office. Head and neck immobilization system. United States patent US 5,988,173 by Scruggs. [cited 2021. accessed 2021 April 5]. Available from URL: https:// uspto.report/patent/grant/7,706,858

14. Wilberger JE. Athletic cervical spinal cord and spine injuries. In: Cantu RC, editor. Neurologic Athletic Head and Spine Injuries. Philadelphia (PA): W.B Saunders Co; 2000. p. 144-152.
15. Zaveri G, Das G. Management of sub-axial cervical spine injuries. Indian J Orthop 2017; 51: 633-652.

16. Schleicher P, Pingel A, Kandziora F. Safe management of acute cervical spine injuries. EFORT Open Rev 2018; 3: 347-357.

17. Feuchtbaum E, Buchowski J, Zebala L. Subaxial cervical spine trauma. Curr Rev Musculoskelet Med 2016; 9: 496-504.

18. Al-Zamanan MY, Al-Yami AS, Al-Najrani AA, Al-Asmari MY, Manaa AA, Al-Qahtani AM, et al. Injury pattern among road traffic accidents' victims in Najran City, Saudi Arabia. Int J Clin Med 2018; 9: 270-280.

19. Dahim MA. Impact of vision 2030 on traffic safety in Saudi Arabia. Int J Pediatr Adolesc Med 2018; 5: 103-109.

20. Samani PP, Athavale NA, Shyam A, Sancheti PK. Awareness of text neck syndrome in young-adult population. Int J Community Med Public Health 2018; 5: 3335-3339.

21. Bangash MH, Saeedi RJ, Al-Ghamdi WA. The Saudi public's knowledge level of spinal injury: a novel risk prediction scoring system. Int J Med Res Heath Sci 2019; 8:114-119. 